\title{
The experience of Cancer survivors to life after Cancer
}

\author{
Sukanya Boonvarasatit ${ }^{1 *}$, Apinya Koontalay ${ }^{2}$, Ponpun Vorasiha ${ }^{3}$ \\ 1, 2,3 Suan Sunandha Rajabhat University, Bangkok, Thailand
}

\section{Key Words: \\ Experience \\ Cancer Survivors \\ Life after Treatment}

Received: 27 May 2016

Accepted: 21 August 2016

Published: 25 October 2016

\begin{abstract}
This qualitative study explored and described the experiences of individuals diagnosed with and suffering from cancer as they transitioned back into ordinary life after treatment as cancer survivors. The sample consisted of 14 cancer survivors in Thailand at least 1 year after treatment. The data were collected during in-depth interviews lasting from 60 to 120 minutes per person for a period of 1 month (January 15 - February 15, 2016). The questions were open-ended in order to gather the perspectives of the participants with regard to their experiences and all data were analyzed by Triangulation technique. The results revealed five major qualitative themes through content analysis of the in-depth interview data. The themes described how the psychological and emotional concerns of the participants changed over time, and were as follows: (1) Family and Social Support, (2) Positive Thinking, (3) Religious Belief, (4) Living in Fear and Uncertainty and (5) Social Isolation. Most people who have survived cancer received support from both their family and society. These findings may help other researchers to use qualitative research with focus groups or in other programs with the aim of helping people survive cancer and enjoy a better quality of life.
\end{abstract}

(c) 2017 The Author(s). Published by TAF Publishing.

\section{INTRODUCTION}

Cancer is a public health problem of global proportions and one which is of concern to all human beings. The World Health Organization [8] found that cancer is the leading cause of death in the entire world and that these numbers will increase every year. In 2013, the International Agency for Research on Cancer [5] a specialized cancer agency within the World Health Organization, released the latest data obtained from GLOBOCAN 2012. This program reported the estimated incidence, prevalence and mortality rate of all forms of cancer (excluding non-melanoma and melanoma) worldwide. The findings indicated that worldwide, there were 14.1 million new cancer cases, 8.2 million deaths from cancer, and 32.6 million people living with cancer (within 5 years of diagnosis) in 2012 worldwide. Significantly, 57\% (8 million) of new cases, 65\% (5.3 million) cancer-related deaths and $48 \%$ (15.6 million) of the prevalent cancer cases within 5 years of diagnosis occurred in less developed regions of the world. At the same time, Thailand has problems that are important to public health. The rate of deaths per 100,000 people in 2007 and 2011 found that the cancer is classified as one of the causes of death of Thailand's population along with a minor accident and heart disease, respectively, and also found that the incidence of cancer increased and the statistics show the top 10 cancer types to be involved. The most common ones in males and females are liver cancer, lung cancer, gastrointestinal large and

\footnotetext{
${ }^{*}$ Corresponding author: Sukanya Boonvarasatit

${ }^{\dagger}$ Email: Sukanya.bo@ssru.ac.th
} 
anal cancer and breast cancer. Cancers that can be prevented, include lung cancer, large intestine and anal cancer and cancer of cervix. However, there are many patients who survived cancer after treatment and can survive more than one year. While the American Cancer Society [1] found that the 5year survival rate refers to the percentage of patients who are alive at least 5 years after their cancer is diagnosed. Many of these people live much longer than 5 years after diagnosis, but the 5 -year rate is used as a standard way to discuss the prognosis. The researchers are interested to find out the meaning and phenomenal experiences of individuals diagnosed with and suffering from cancer as they transitioned from life with cancer to life after treatment as cancer survivors for a period of more than 1 year after treatment. This study was to improve the care of these individuals as they transitioned into life after surviving cancer. As a result, this study was intentionally exploratory and descriptive how the psychological and emotional concerns of the participants changed over time.

\section{METHODOLOGY}

\section{Study Design}

This study is a qualitative research using in-depth interviews to explore and explain the experience of the cancer survivors. Examination by a group of researchers (peer debriefing) and checked by trace evidence (audit trail) that arises from doing such research journal observations in the field (field note) and a copy of the transcript of words of interview (interview transcript) are completed.

\section{Study Population}

A purposive sampling procedure was used. Criteria for inclusion were cancer survivors for a period of more than 1 year after treatment living in urban and rural areas of Thailand. Finally, the study population comprised 14 cancer survivors at least 1 year after treatment (from 1 to 15 years); 2 males and 12 females, age 36 - 89 years. They were Buddhists in Thailand and the majority had married. They were willing to participate in this study.

\section{Data Collection Procedures}

One researcher conducted 14 in-depth interviews lasting from 60 to 120 minutes per person for a period of 1 month (January 15 - February 15, 2016). All interviews were recorded and transcribed verbatim. An interview guide was used to ensure that common themes and topics were explored during the interview. The questions were open-ended in order to gather the perspectives of the participants regarding their experiences. The interview questions were designed to draw attention to the ways in which the psychological and emotional concerns of cancer survivors changed over time, which also included details about the social lives of cancer survivors. For example, the researchers asked the survivors to describe their perspective in terms of the following aspects: whether or not, in their experience, their psychological and emotional concerns changed over time; how they managed their medical care, including information about the individuals (friends, family and colleagues) and agencies (health care professionals) who cared for them; the ways in which these individuals and agencies either helped or hindered their management of their illness; how they dealt with their treatment from initial diagnosis till the time of this study; how their health and well-being have changed over time, especially the period from when they finished their treatment till the present day; and how the emotional and social challenges they experienced have changed over the time period from when their cancer treatment ended until the time this study was conducted. 


\section{Analysis of Data}

Monitoring data before analysis by examining the data while keeping data in the field and checking again when leaving the field are achieved in this process. Based on theoretical saturation, all data were proceeded simultaneously, until it was judged that no new information was obtained and all data were analyzed by Triangulation technique.

\section{RESULTS}

The findings revealed five major qualitative themes through content analysis of the indepth interview data. The themes described how the psychological and emotional concerns of the participants changed over time.

\section{Family and Social Support}

A survivor's perception of available social support is important across all facets of survivorship. Thewes et al. [6] at the same time, a study on the Epidemiology of Lung Cancer Prognosis: Quantity and Quality of Life of Yang [9] found that New knowledge to be gained should help lung cancer survivors, their healthcare providers, and their caregivers by providing evidence for establishing clinical recommendations to enhance their long-term survival and health-related QOL. Two of the cancer survivors said: "When I know myself as a cancer patient, I was very sad and could not accept what happened. But I've been encouraged by all the family. My husband held my hand. My son came to hug me. They told me that we will fight against cancer together. I am encouraged more and not worried anymore. Now I have become a survivor from cancer five years ago. The family and social support gave me courage to live in this world and to be happy." (Breast Cancer Survivor). "Since my family knew I was sick with cancer, they never let me go to the doctor alone. I had a chance to get up close with three daughters, I love them very much. Every time I looked at my wife and my family, I tried to maintain a healthy living with them for so long." (Prostate Cancer Survivor). However, a study on the Social Networks, Social Support, and Survival After Breast Cancer Diagnosis of Kroenke et al. [10] found that conclusions were that socially isolated women had an elevated risk of mortality after a diagnosis of breast cancer, likely because of a lack of access to care, specifically beneficial care given by friends, relatives, and adult children.

\section{Positive Thinking}

Many patients and survivors have to worry about the cancer coming back after treatment. Evidence suggests that positive lifestyle changes during and after cancer treatment may help prevent a recurrence [2]. Two of the cancer survivors said: "Now, I'm stronger than when the cancer had disappeared. And I feel proud of myself that I can live like normal people." (Breast Cancer Survivor). "I always told myself I have to live for my family." (Breast Cancer Survivor)

\section{Religious Belief}

Based on the findings of Lynn Gall et al. [4] it is found that "The majority of women discussed the positive role of various spiritual resources in their response to the experience of cancer, including relationship with God, religious coping activities (e.g. prayer), meaning and social support. A cognitive model of adjustment was proposed which shows how spiritual resources can help breast cancer survivors make meaning of and experience a sense of life affirmation and personal growth in relation to the cancer". Thailand's population is mostly Buddhist. Culture of Thailand has the practice of continuing to come together to do 
religious activities at the temple and the prayer can follow the example of Buddhism. Buddhism is an anchor for the soul of the people of Thailand. However, the results revealed that the majority of cancer patients had spiritual needs falling within the high level Pornpun et al . [3]. Two of the cancer survivors said: "I am Buddhist. I pray every night before bed. I think that prayer makes me more calm-minded." (Colon Cancer Survivor). "Before cancer, I never liked the prayer. One day, while I was feeling that cancer had taken my life, the doctor told me to chill out. I had doctor's appointments every time. But I was still worried. I tried every way to calm the mind. The Buddhist prayers and intentions were my choice then. I pray every day, sitting in a calm place, everything in my life is really better." (Ovarian Cancer Survivor)

\section{Living in Fear and Uncertainty}

Many cancer survivors live with some uncertainty about their future. Experience in the treatment of cancer patients varies depending on the type of illness. When the people who survive cancer are feeling less confident in their own living after treatment, health care providers need to have a holistic approach for support care [7]. However, The American Cancer Society [1] recommends some ideas that have helped others deal with uncertainty and fear and feel more hopeful such as; express feelings of fear or uncertainty to a trusted friend or counselor. Being open and dealing with emotions helps many people feel less worried. People have found that when they express strong feelings, like fear, they are more able to let go of these feelings. Two of the cancer survivors said:" I am married for many years but have never had children. When I was informed by the hospital that my patient has ovarian cancer, I was very sorry. I asked myself all the time that I will stay for another few days. Many doctors and nurses tried to explain to me how to maintain it. For the past five years, I have never felt the same. The illness was also a big nightmare for me all along." (Survivor of Cervix Cancer)."Before I had cancer, my boss praised me because I always worked very hard. But now I cannot work the same. I do not want to lose the job, but my body is not strong as before. I fear the cancer again. I want to perform well, but the same cannot be so sure." (Breast Cancer Survivor)

\section{Social Isolation}

Isolation from society, having survived from cancer, may be due to several reasons that vary. However, a study on the Social Networks, Social Support, and Survival after Breast Cancer Diagnosis of [10] found that socially isolated women had an elevated risk of mortality after a diagnosis of breast cancer, likely because of a lack of access to care, specifically beneficial caregiving from friends, relatives, and adult children. Two of the cancer survivors said: "After my cancer was gone, Depression lasted for one year. Since then, I did not meet anyone. I did not want to talk to anyone and I kept alone." (Breast Cancer Survivor). "Two years ago I would not want to meet anybody. I wanted to wear beautiful clothes. But I did not have hair." (Breast Cancer Survivor)

\section{CONCLUSION}

The result findings demonstrated of (1) Family and Social Support, (2) Positive Thinking, (3) Religious Belief, (4) Living in Fear and Uncertainty and (5) Social Isolation. Most people who have survived cancer received support from both their family and society. These findings may help other researchers to use qualitative research with focus groups or in other programs with the aim of helping people survive cancer and enjoy a better quality of life. 


\section{ACKNOWLEDGMENT}

The researchers would like to thank all the experts who kindly provided the valuable advices. Thanks to Research and Development Institute, Suan Sunandha Rajabhat University and College of Nursing and Health who gave funding for doing this research and cooperation of all participants.

\section{REFERENCES}

1. American Cancer Society. Living with uncertainty: The fear of cancer recurrence . 2013. Available from: goo.gl/nDTi1Y

2. American Society of Clinical Oncology. Healthy living after Cancer: Approved by the Cancer. 2015. Available from: goo.gl/WL7jA

3. Pornpun W, Jamrak L, Augkarb S, Patira B, Pratumporn SCB. Spiritual needs of cancer patients and spiritual support needs from nurses. Paper presented at: The Annual Conference 2009 of the Department of Nursing. Siriraj Hospital, Thailand, TH. 2009.

4. Lynn Gall T, Cornblat MW. Breast cancer survivors give voice: A qualitative analysis of spiritual factors in long-term adjustment. Psycho-Oncology . 2002; 11(6): 524-535. DOI: 10.1002/pon.613

5. The International Agency for Research on Cancer. Latest world cancer statistics global Cancer. 2013. Available from: goo.gl/YcjEdV

6. Thewes B, Bell ML, Butow P, Beith J, Boyle F, Friedlander M, McLachlan SA. Psychological morbidity and stress but not social factors influence level of fear of cancer recurrence in young women with early breast cancer: results of a crosssectional study. Psycho-Oncology. 2013; 22(12): 2797-2806. DOI: 10.1002/pon.3348

7. Wichitra K. Critical care nursing: A holistic approach. Bangkok, TH: A United Nations of Commerce. 2008.

8. World Health Organization. All Cancers (excluding non-melanoma skin cancer) estimated incidence, mortality and prevalence world wide .2012. Available from: goo.gl/I4mqie

9. Yang P. Epidemiology of lung cancer prognosis: quantity and quality of life. Cancer Epidemiology. 2009; 47(1): 469- 486. DOI: 10.1007/978-1-59745-416-224

10. Kroenke CH, Kubzansky LD, Schernhammer ES, Holmes MD, Kawachi I. Social networks, social support, and survival after breast cancer diagnosis. Journal of Clinical Oncology. 2006; 24(7): 1105-1111. DOI: 10.1200/JC0.2005.04.2846 